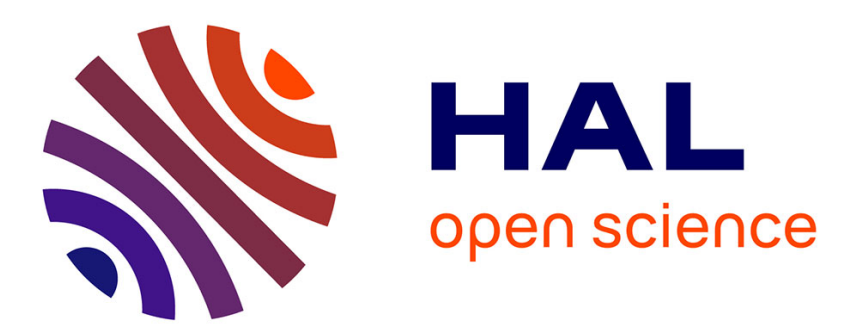

\title{
Chemoselective H/D Exchange Catalyzed by Nickel Nanoparticles Stabilized by N-Heterocyclic Carbene Ligands
}

Donia Bouzouita, Juan Manuel Asensio, Viktor Pfeifer, Alberto Palazzolo, Pierre Lecante, Grégory Pieters, Sophie Feuillastre, Simon Tricard, Bruno Chaudret

\section{To cite this version:}

Donia Bouzouita, Juan Manuel Asensio, Viktor Pfeifer, Alberto Palazzolo, Pierre Lecante, et al.. Chemoselective H/D Exchange Catalyzed by Nickel Nanoparticles Stabilized by N-Heterocyclic Carbene Ligands. Nanoscale, 2020, 10.1039/D0NR04384B . hal-02903879

\section{HAL Id: hal-02903879 https://hal.science/hal-02903879}

Submitted on 21 Jul 2020

HAL is a multi-disciplinary open access archive for the deposit and dissemination of scientific research documents, whether they are published or not. The documents may come from teaching and research institutions in France or abroad, or from public or private research centers.
L'archive ouverte pluridisciplinaire HAL, est destinée au dépôt et à la diffusion de documents scientifiques de niveau recherche, publiés ou non, émanant des établissements d'enseignement et de recherche français ou étrangers, des laboratoires publics ou privés. 


\title{
Chemoselective H/D Exchange Catalyzed by Nickel Nanoparticles Stabilized by $N$-Heterocyclic Carbene Ligands
}

\author{
Donia Bouzouita, ${ }^{a}$ Juan M. Asensio, ${ }^{a^{*}}$ Viktor Pfeifer, ${ }^{b}$ Alberto Palazzolo, ${ }^{b}$ Pierre Lecante,${ }^{c}$ \\ Grégory Pieters, ${ }^{\mathrm{b}}$ Sophie Feuillastre, ${ }^{\mathrm{b}}$ Simon Tricard ${ }^{\mathrm{a}^{*}}$ and Bruno Chaudret. ${ }^{\mathrm{a}^{*}}$
}

\author{
${ }^{a}$ D. Bouzouita, J.M. Asensio, S. Tricard, B. Chaudret. LPCNO; Université de Toulouse, \\ INSA-CNRS-UPS, Institut National des Sciences Appliquées, 135, Avenue de Rangueil, 31077 \\ Toulouse (France). \\ E-mail: chaudret@insa-toulouse.fr,tricard@insa-toulouse.fr, asensior@insa-toulouse.fr \\ ${ }^{b}$ V. Pfeifer, A. Palazzolo, S. Feuillastre, G. Pieters. SCBM, CEA, Université Paris Saclay, F- \\ 91191, Gif-sur-Yvette, (France). \\ ${ }^{c}$ P. Lecante: CEMES (Centre d'Elaboration de Matériaux et d'Etudes Structurales), CNRS, \\ 29 Rue J. Marvig, F-31055 Toulouse, (France).
}

With this work, we report the synthesis and full characterization of nickel nanoparticles (NPs) stabilized by $N$-heterocyclic carbene (NHC) ligands, namely 1,3-bis(cyclohexyl)-1,3-dihydro2H-imidazol-2-ylidene (ICy) and 1,3-bis(2,4,6-trimethylphenyl)-1,3-dihydro-2H-imidazol-2ylidene (IMes). Although the resulting NPs have the same size, they display different magnetic properties and different reactivities, which result from ligand effects. In the context of H/D exchange on pharmaceutically relevant heterocycles, Ni@NHC shows a high chemoselectivity, avoiding the formation of undesired reduced side-products and enabling a variety of $H / D$ exchange on nitrogen-containing aromatic compounds. Using 2phenylpyridine as a model substrate, it was observed that deuteration occurred preferably at the $\alpha$ position of the nitrogen atom, which is the most accessible position for the $\mathrm{C}-\mathrm{H}$ activation. In addition, Ni@IMes NPs are also able to fully deuterate the ortho positions of the phenyl substituents.

\section{Introduction}

Hydrogen isotope exchange reactions are presently widely studied since the applications of organic molecules labelled with deuterium and tritium atoms have significantly increased during the last decades. ${ }^{1}$ Particularly, deuterium-labelled compounds are of high interest in life sciences, ${ }^{2}$ as kinetic isotopic effects can for example significantly influence the pharmacokinetic behavior of drugs or reduce their toxicity. ${ }^{3}$ The development of efficient methods to perform such reactions in mild conditions, and to have a good control on reaction selectivity is therefore essential. ${ }^{4}$ Thus, $\mathrm{C}-\mathrm{H}$ activation catalyzed by different metal complexes for H/D exchange has emerged as a powerful tool. For instance, $\mathrm{Ir}^{5,6} \mathrm{Ru},{ }^{7-9} \mathrm{Rh},{ }^{10}$ $\mathrm{Pd}^{11}$ or $\mathrm{Pt}^{12}$ complexes have been described in literature as efficient catalysts for $\mathrm{H} / \mathrm{D}$ exchange reactions in homogeneous phase. Very recently, Zarate et al. have shown that $\mathrm{Ni}$ (II) 
and $\mathrm{Ni}(\mathrm{I})$ complexes functionalized with bulky diimines are active catalysts for $\mathrm{H} / \mathrm{D}$ exchange reactions in pharmaceuticals. ${ }^{13,14}$ Heterogeneous catalysts have also been widely employed in H/D exchange, with the advantage of an easy removal and recyclability of the catalyst. Amongst different metals, the most employed are $\mathrm{Pd}$, $\mathrm{Pt}$ and $\mathrm{Ru}$, all supported on carbon $(\mathrm{Pd} / \mathrm{C}, \mathrm{Pt} / \mathrm{C}$ and $\mathrm{Ru} / \mathrm{C}) .{ }^{15-16}$ However, to the best of our knowledge, only few examples of H/D exchange catalyzed by metal nanoparticles (MNPs) have been reported to date, while abundant and less costly first row transition metal NPs have never been used for this purpose, ${ }^{4}$ although a few examples of H/D exchange catalyzed by Raney Nickel are known. ${ }^{17,18}$

MNPs have shown to be very efficient catalysts due to their unique electronic properties and the possibility to modulate their size, shape and composition, thus permitting control of their catalytic properties. In addition, upon adjusting the nature of the stabilizing ligands at the surface of the NPs, the reactivity, solubility or selectivity of the system can be easily tuned, which constitutes an advantage over the classical heterogeneous catalysts. MNPs are well-known catalysts for the H-H and D-D activation ${ }^{19-22}$ and, therefore, they have been widely employed in catalytic hydrogenation. ${ }^{23} \mathrm{~A}$ more recent development of MNPs reactivity is $\mathrm{C}-\mathrm{H}$ activation in mild conditions, which may present several potential applications. ${ }^{24,25}$ The combination of these reactivities may render the NPs active catalysts for H/D exchange, which in turn can serve as a good model reaction to understand the surface reactivity and selectivity of the MNPs. ${ }^{26}$ For instance, our research groups have already shown that $\mathrm{Ru}$ NPs can efficiently catalyze $\mathrm{C}-\mathrm{H}$ activation reactions leading to selective deuterium incorporation into several nitrogen-containing compounds such as pyridines, indoles, alkylamines, etc. ${ }^{27,28}$ Later on, it was shown that Ru and RuPt NPs are good catalysts for the enantiospecific deuteration of peptides at the $\alpha$ position of nitrogen atoms. ${ }^{24-29}$ However, a typical limitation of Ru-based NPs in H/D exchange reactions is their high reactivity towards aromatic rings, leading, in some cases, to the formation of considerable amounts of undesired reduced side-products. ${ }^{30,} 31$ In this respect, Ni NPs, less prone to hydrogenate aromatic rings, can appear as a more earth-abundant and less-costly alternative to $\mathrm{Ru}$ NPs for H/D exchange reactions.

$N$-heterocyclic carbenes (NHCs) are versatile ligands that have been widely used for the synthesis of a broad variety of metallic complexes or for the functionalization of metallic surfaces. ${ }^{32-38}$ During the last years, NHCs have also shown to be very efficient ligands that strongly coordinate to the surface of MNPs, permitting to modulate their catalytic activity and selectivity. ${ }^{39-44}$ MNPs stabilized by NHCs have previously been employed as catalysts in H/D exchange reactions. We have previously observed that Ru NPs stabilized by water-soluble NHC ligands showed a remarkable activity for the enantiospecific deuteration of L-lysine in aqueous solution, ${ }^{45}$ as well as for selective labelling of drug candidates and nucleobase derivatives. ${ }^{46}$ Recently, Godard and co-workers reported the synthesis of Ni NPs stabilized by NHC ligands through thermal decomposition of a $\mathrm{NHC}-\mathrm{CO}_{2}$ adduct, used as catalysts for alkyne hydrogenation. ${ }^{47}$ However, to the best of our knowledge, Ni NPs have never been used as catalysts in H/D exchange reactions so far.

In this work, we have synthesized Ni NPs stabilized by bulky NHC ligands and compared their catalytic activity and selectivity for the deuteration of 2-phenylpyridine. $\mathrm{Ni} @ \mathrm{NHC}$ NPs are used for the first time as catalysts for C-H activation, and it is shown that they can selectively deuterate 2-phenylpyridine without reducing aromatic rings, which is the 
most important limitation of Ru@NHC NPs. Finally, deuteration of a substrate scope containing different $N$-heterocycles has been performed, leading to excellent chemoselectivities in all cases.

\section{Results and discussion}

\section{Synthesis and characterization of Ni@NHC NPs}

$\mathrm{Ni} @ \mathrm{NHC}$ NPs have been synthesized by decomposition of $\mathrm{Ni}(\mathrm{COD})_{2}$ under 3 bar of $\mathrm{H}_{2}$ in THF at $70{ }^{\circ} \mathrm{C}$, in the presence of 0.25 equivalents of free 1,3-bis(cyclohexyl)-1,3-dihydro- $2 \mathrm{H}$ imidazol-2-ylidene (ICy - NPs 1), obtained after deprotonation of the corresponding imidazolium salt with $\mathrm{KO}^{\mathrm{t}} \mathrm{Bu}$; or in the presence of 0.25 equivalents of 1,3-bis $(2,4,6-$ trimethylphenyl)-1,3-dihydro- $2 H$-imidazol-2-ylidene (IMes - NPs 2) (Scheme 1). The Ni NPs were characterized by transmission electron microscopy (TEM). TEM micrographs revealed the presence of small Ni@NHC NPs with mean sizes of $2.0 \pm 1.0 \mathrm{~nm}$ and $1.8 \pm 0.6 \mathrm{~nm}$ for NPs 1 and 2 respectively (Fig. 1). NPs 1 and 2 were further characterized by Inductively Coupled Plasma-Mass Spectrometry (ICP-MS, see Experimental Section in ESI) and WideAngle X-Ray Scattering (WAXS). The diffractograms of NPs 1-2 (Fig. 2) showed peaks corresponding to $f c c-\mathrm{Ni}(0)$, although few residual traces of $\mathrm{NiO}$ were observable in the case of NPs 1. Radial Distribution Functions (RDF) analyses showed Ni-Ni distances of $0.25 \mathrm{~nm}$ for NPs 1-2 in agreement with the $f c c-\mathrm{Ni}(0)$ structure above proposed (Fig. S1-2).
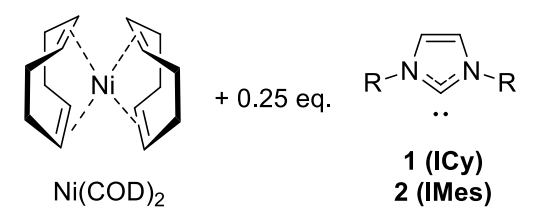

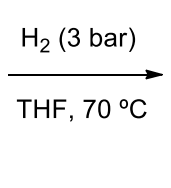

R.

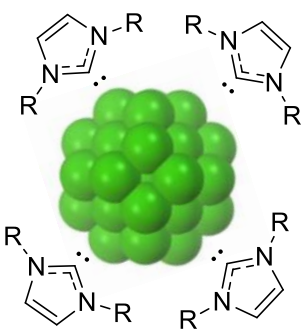

$1 \mathrm{Ni@ICy:} 2.0 \pm 1.0 \mathrm{~nm}$ 2 Ni@IMes: $1.8 \pm 0.6$ nm

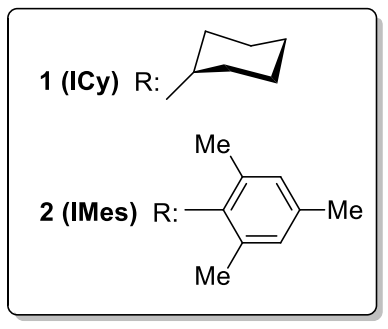



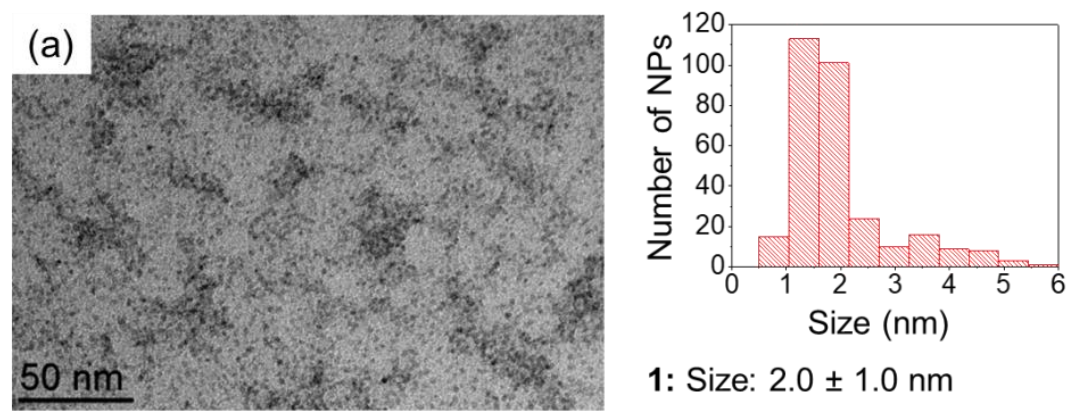

1: Size: $2.0 \pm 1.0 \mathrm{~nm}$

(b)
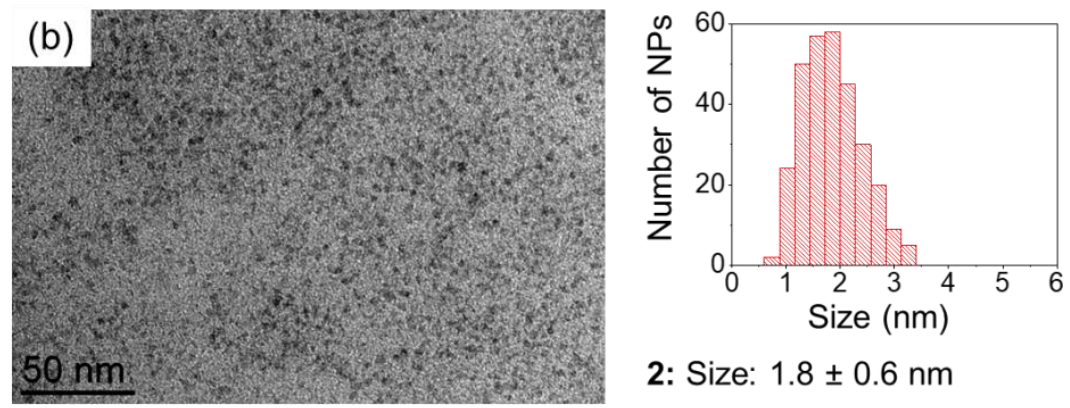

2: Size: $1.8 \pm 0.6 \mathrm{~nm}$

Fig. 1 TEM images and size distributions for NPs (a) Ni@ICy 1 and (b) Ni@IMes 2.
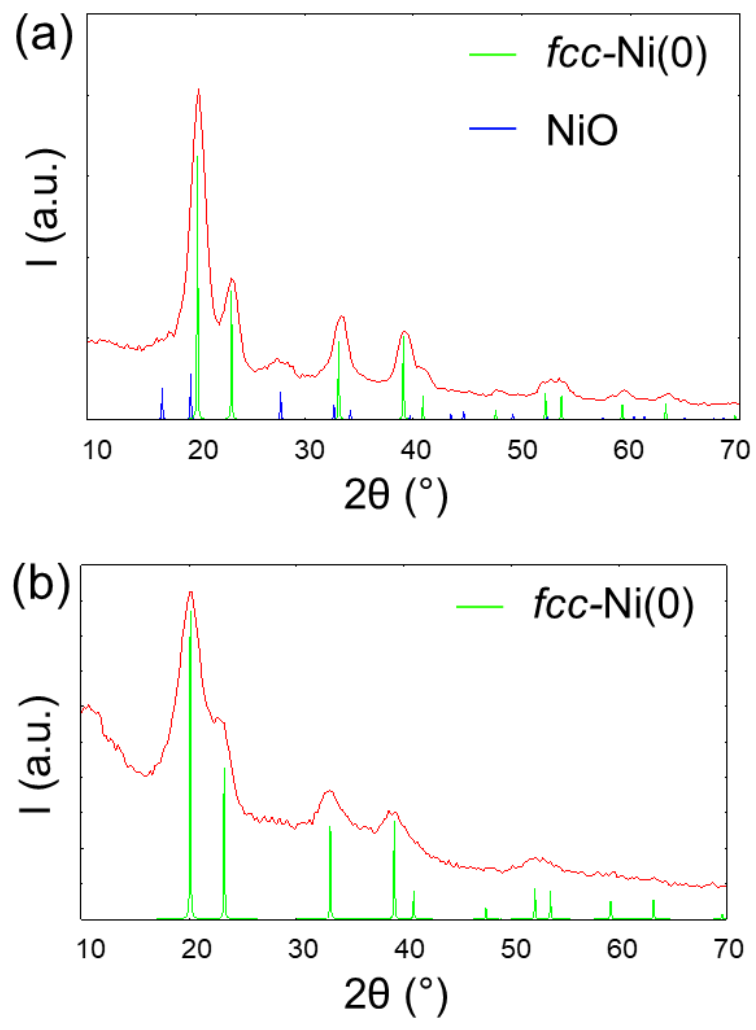

Fig. 2 XRD diffractograms for (a) Ni@ICy NPs 1 and (b) Ni@ IMes NPs 2.

The magnetic properties of NPs 1-2 were determined by Vibrating Sample Magnetometry (VSM). The two systems are superparamagnetic at $300 \mathrm{~K}$ and ferromagnetic at $5 \mathrm{~K}$, but display magnetization $(M)$ values at a $\mu_{0} \mathrm{H}$ of $3 \mathrm{~T}$ at $300 \mathrm{~K}$ below the one reported for $\mathrm{Ni}$ bulk $\left(55 \mathrm{~A} \cdot \mathrm{m}^{2} \cdot \mathrm{kg}^{-1}\right){ }^{48}$ Indeed, the magnetization vs. applied field curves for Ni@NHC 
NPs display a $M$ value of $23 \mathrm{~A} \cdot \mathrm{m}^{2} \cdot \mathrm{kg}^{-1}$ at $300 \mathrm{~K}$ at a $\mu_{0} H$ of $3 \mathrm{~T}$ for NPs 1 whereas it is only of $5 \mathrm{~A} \cdot \mathrm{m}^{2} \cdot \mathrm{kg}^{-1}$ for NPs 2 (Fig. 3). In both cases, the depletion in the magnetization can be explained by the high surface/magnetic-core ratio resulting from the small size of the Ni NPs, and for which a higher proportion of non-magnetic layers located at the NP surface can be present. ${ }^{49}$ The important differences in the $M$ values between NPs $\mathbf{1}$ and $\mathbf{2}$ at a $\mu_{0} H$ of $3 \mathrm{~T}$ (23 and $5 \mathrm{~A} \cdot \mathrm{m}^{2} \cdot \mathrm{kg}^{-1}$ respectively) probably arise from a ligand effect, as the mean sizes measured by TEM for both systems are within the same range. It has previously been observed that the magnetic moment of $\mathrm{Ni}$ is highly sensitive to ligand effects. $\pi$-acceptor ligands, such as CO, can strongly decrease the $M$ value. ${ }^{50,51}$ Therefore, the $M$ differences between both systems can serve as an indication of the higher $\pi$-acceptor capacity of the IMes ligand with respect to the ICy ligand, which is in agreement with previous observations. ${ }^{52}$

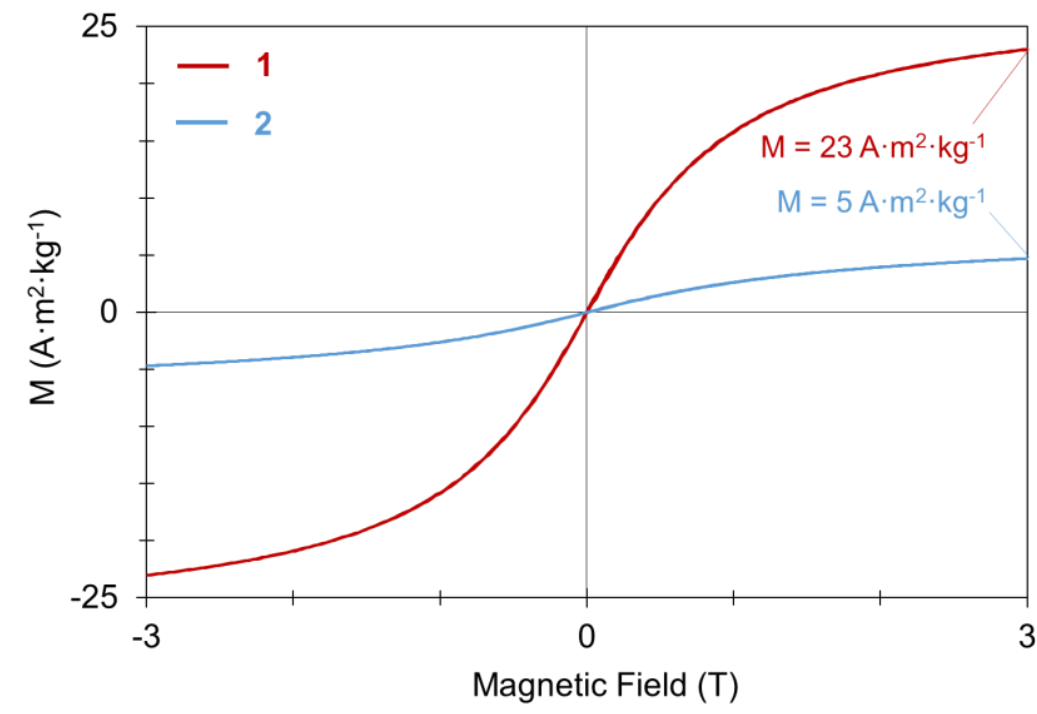

Fig. 3 Comparison of the magnetization vs. applied magnetic fields curves for Ni@ICy NPs 1 (red curve) and Ni@IMes NPs 2 (blue curve) at $300 \mathrm{~K}$.

\section{Optimization of the reaction conditions for the deuteration of 2-phenylpyridine}

The catalysts 1 and $\mathbf{2}$ were evaluated for the deuteration of 2-phenylpyridine under 2 bar of $\mathrm{D}_{2}$ using $12 \mathrm{~mol} \%$ of catalyst loading (see Table 1). 2-phenylpyridine was chosen as a model substrate because it can coordinate to the surface of the MNPs through the nitrogen donor atom, and it contains two aromatic rings that are susceptible to be reduced under a $D_{2}$ atmosphere. For the sake of comparison, Ru NPs are very active catalysts for the hydrogenation of aromatic substrates even at low temperatures. When performing the deuteration of 2-phenylpyridine using the Ru@ICy NPs as catalysts at $55{ }^{\circ} \mathrm{C}$, the total reduction of the aromatic moieties was observed after $24 \mathrm{~h}$ (entry 1 and Fig. S3). Ru@ICy NPs are thus non-adequate catalysts to perform H/D exchange, as they imply the formation of undesired reduced products in these conditions. 
Table 1 Optimization of the reaction conditions for the deuteration of 2-phenylpyridine catalyzed by Ni@NHC.

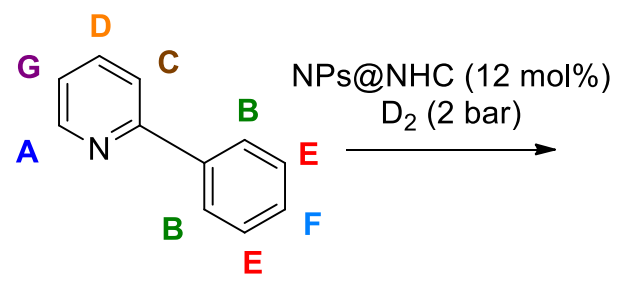

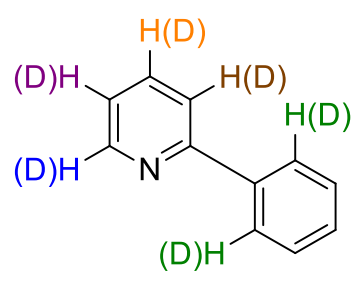

\begin{tabular}{|c|c|c|c|c|c|c|c|c|}
\hline \multirow{2}{*}{ Entry } & \multirow{2}{*}{ Catalyst } & \multirow{2}{*}{ Solvent } & \multirow{2}{*}{$\mathbf{T}\left({ }^{\circ} \mathbf{C}\right)$} & \multirow{2}{*}{$\begin{array}{l}\text { Time } \\
\text { (h) }\end{array}$} & \multicolumn{4}{|c|}{ Isotopic enrichment (\%) } \\
\hline & & & & & $\mathbf{A}$ & $\mathbf{B}$ & $\mathbf{C}+\mathbf{D}^{\mathbf{a}}$ & $\mathbf{G}$ \\
\hline 1 & Ru@ICy & THF & 55 & 24 & \multicolumn{4}{|c|}{ Complete reduction } \\
\hline 2 & 1 & THF & 55 & 5 & 64 & 4 & - & - \\
\hline 3 & 1 & THF & 55 & 24 & 95 & 12 & - & - \\
\hline 4 & 1 & THF & $\mathrm{rt}$ & 24 & 55 & 5 & - & - \\
\hline 5 & 1 & pentane & 55 & 24 & 96 & 17 & - & - \\
\hline 6 & 1 & toluene & 55 & 24 & 96 & 14 & - & - \\
\hline 7 & 2 & THF & 55 & 24 & 95 & 99 & 11 & 14 \\
\hline 8 & 2 & THF & 55 & 5 & 37 & 40 & - & - \\
\hline 9 & $3^{\mathrm{b}}$ & THF & 55 & 24 & 95 & 75 & - & - \\
\hline
\end{tabular}

General catalytic conditions: $0.15 \mathrm{mmol}$ of the corresponding substrate and 2-3 $\mathrm{mg}$ of the NPs (12 mol\%) were dissolved in $1 \mathrm{~mL}$ of THF in a Fischer-Porter bottle. Then, the reaction mixture was pressurized with $\mathrm{D}_{2}$ (2 bar) for the indicated time. The conversion and yield were determined by ${ }^{1} \mathrm{H}$ NMR and mass spectrometry. ${ }^{a}$ The NMR signals of $\mathrm{C}$ and $\mathrm{D}$ positions were impossible to distinguish with a $400 \mathrm{MHz}$ NMR spectrometer; the isotopic enrichment is given for both positions. ${ }^{\mathrm{b}}$ The solution containing the substrate and the catalyst 2 was stirred under air for 5 minutes, and led to the catalyst called 3 , before loading the 3 bar of $\mathrm{D}_{2}$.

Ni@ICy NPs 1 showed high activity in the deuteration of the 2-phenylpyridine at 55 ${ }^{\circ} \mathrm{C}$ in THF solution. Indeed, 64\% isotopic enrichment at position A was observed after 5 hours (entry 2). After 24 hours, we observed a 95\% isotopic enrichment for position A, together with $12 \%$ of deuteration for position B (entry 3, Fig. S4-6). Interestingly, the reaction occurred without any reduction of the aromatic rings. The NPs 1 were also active at room temperature (entry 4), and $55 \%$ of isotopic enrichment at position A was observed after 24 hours. The reaction is tolerant towards the use of other non-polar solvents, similar deuteration degrees were obtained when performing the reactions in pentane or toluene at $55{ }^{\circ} \mathrm{C}$ (entries $5-6)$. 
The Ni@IMes NPs 2 were more active in H/D exchange on 2-phenylpyridine under similar reaction conditions (entry 7, Fig. S7-8). Indeed, 95\% deuteration of position A was accompanied by a complete deuteration of position B. Deuterium incorporations of 11 and $14 \%$ were also observed for the C-D and G positions respectively. Similar deuteration proportions were found for the position A and the position B after $5 \mathrm{~h}$ of reaction with NPs 2 (entry 8). This behavior contrasts with NPs 1, where a strong preference for the labelling of position A is observed, regardless the experimental conditions. When the reaction mixture containing the NPs 2 was stirred under air for 5 minutes before loading the 2 bar of $\mathrm{D}_{2}$ (NPs 3), almost the same activity was found for position A but decrease of deuteration was observed for position B (entry 9).

Overall, these results first demonstrate that $\mathrm{Ni}$ nanoparticles are very active for $\mathrm{C}-\mathrm{H}$ activation in mild conditions. This property is used for achieving selective H/D exchange reactions, but the scope of this reactivity is likely to be larger. Then, a significant difference of selectivity for deuteration of 2-phenylpyridine can be observed between the catalysts $\mathbf{1}$ and 2 although they display the same size and contain similar ligands. It has previously been proposed that the mesityl groups of the IMes ligands may interact with metallic Au surfaces through $\pi$-interactions, and this can leave enough space for another molecule to approach the NPs surface. ${ }^{53}$ This phenomenon is likely to occur with Ni surfaces also. In contrast, ICy ligand would adopt a configuration in which the cyclohexyl substituents are pointing away from the NP and hence can give rise to a more compact organization. In this respect, the steric hindrance induced by the ICy ligand would only allow 2-phenylpyridine to approach the $\mathrm{Ni}$ surface of catalyst 1 through the pyridine ring (end-on) whereas the space on the surface could allow side-on coordination or even flat coordination of the aromatic rings on catalyst 2 (Scheme 2). A somewhat similar effect has been observed in hydrogenation reactions involving Ru NPs stabilized long chain NHCs bearing mesityl substituents. ${ }^{54}$ The catalytic mechanism is likely to involve oxidative addition in a variety of approaches: (i) a fourmembered ring for the deuteration of position $A$ as proposed for $\operatorname{Ru}(0) \mathrm{NPs}^{29}$ for NPs 1 and 2 or (ii) a five- or six-membered ring depending on the number of $\mathrm{Ni}$ atoms implied, ${ }^{55}$ for the deuteration of position B using NPs 2 (Scheme 2 shows the six-membered metallacycle); and (iii) after $\pi$-coordination of the pyridyl ring, a more complex mechanism can act, which has not been elucidated here. It is interesting to note that the other positions of the phenyl ring are not deuterated which probably emphasizes the importance of the coordination through nitrogen atom for the $\mathrm{C}-\mathrm{H}$ activation to proceed. Interestingly, the system is tolerant to oxygen. Indeed, when a solution of a mixture of catalyst $\mathbf{2}$ and 2-phenylpyridine was stirred in open air for 5 minutes prior to addition of deuterium (NPs 3), only a decrease of isotopic enrichment of the position B from 95 to $75 \%$ was observed. This system can thus be operated in non-strictly anaerobic conditions. 


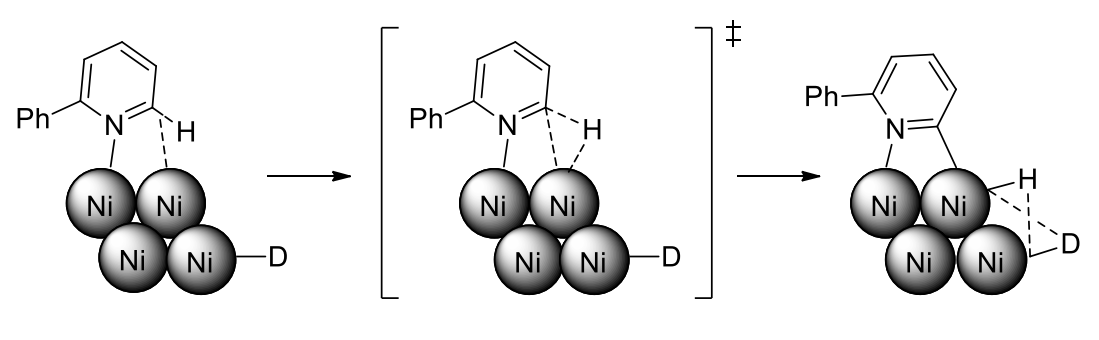

Oxidative Addition

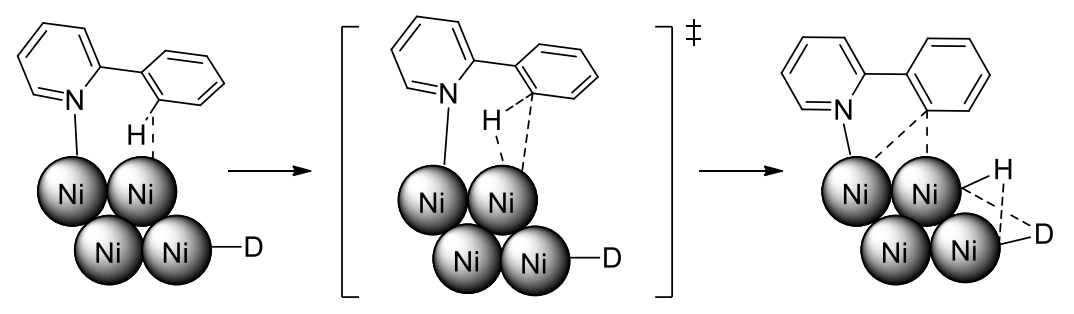

Scheme 2 Proposed mechanism for the $\mathrm{C}-\mathrm{H}$ activation catalyzed by $\mathrm{Ni}(0)$ : $\mathrm{C}-\mathrm{H}$ activation would follow an oxidative addition into a $\mathrm{Ni}(0)$ to give a 4-membered or a 5- or 6-membered metallacycle which would lead to deuteration in positions A or B.

\section{Scope of substrates}

After optimization of the reaction conditions for 2-phenylpyridine, the scope of substrates was extended for the most active catalyst, Ni@IMes NPs 2 (12 mol\% of catalyst), under 2 bar of $\mathrm{D}_{2}$ at $55^{\circ} \mathrm{C}$ in THF (Table 2 and Fig. S9-22). In this context, the deuteration of different pharmaceutically relevant heterocycles was explored. In all cases, the deuterium incorporation preferentially took place at the $\alpha$-positions of the nitrogen atom. For instance, isotopic enrichment was $100 \%$ for pyridine (4) in positions 2 and 6 . A minor amount of $7 \%$ of deuterium uptake was also observed in the position 4. Similarly, an isotopic enrichment of 97\% for the $\alpha$-position of phenantroline (5) and 2,2'-bipyiridyl (6) was obtained, although some deuterium incorporation was also observed for other positions of the molecules (Table 2). These results obtained with pyridine and phenantroline strongly suggest that, as for 2phenylpyridine, another mechanism than the classical coordination through the nitrogen atom $^{27}$ may also occur, very likely after $\pi$-coordination of the substrate. Interestingly, in the case of 2-phenylimidazole (7), deuteration was faster for the ortho-positions of the aromatic ring (92\% of isotopic enrichment) than for the positions of the imidazole ring (50\% of isotopic enrichment). 1-phenyl- $1 H$-1,2,4-triazole (8) was completely deuterated at the 5position of the triazole ring and $67 \%$ of deuteration was obtained for the 3-position. However, in this case, no deuteration was observed on the phenyl substituent, which suggests that coordination occurs preferentially through the 4-N atom of the 1,2,4-triazole unit.

Finally, we studied the isotopic enrichment on other heterocycles also containing oxygen atoms. In the case of 5-(p-tolyl)oxazole (9), a total deuteration at the most acidic 2position of the aromatic ring was observed, along with $22 \%$ of isotopic enrichment at position 4. The absence of deuteration at the ortho-position of the phenyl substituent evidences that 
coordination preferentially takes place through the nitrogen atom of this substrate, and not through the oxygen atom. For 2,4-diphenyloxazole (10), deuteration was almost complete at position 4 of the aromatic ring as well as at the ortho-position of the 2-phenyl substituent, evidencing again that the coordination through nitrogen atom is preferred. Interestingly, no reduced side-product of $\mathbf{1 0}$ was detected here, whereas the use of Ru NPs as catalysts on this substrate lead to lower isotopic enrichments and an isolated yield of $25 \%{ }^{49}$

Table 2 Scope of substrates catalyzed by Ni@IMes NPs 2.

$$
\text { Heterocycle-H } \underset{\substack{\mathrm{THF}, 55^{\circ} \mathrm{C} \\ 24 \mathrm{~h}}}{\stackrel{2(12 \mathrm{~mol} \%)}{\mathrm{D}_{2}(2 \mathrm{bar})}} \text { Heterocycle-D }
$$

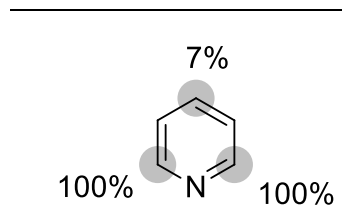

4

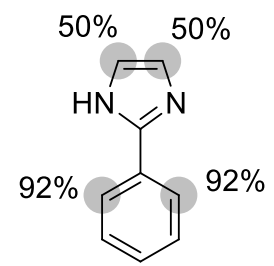

7
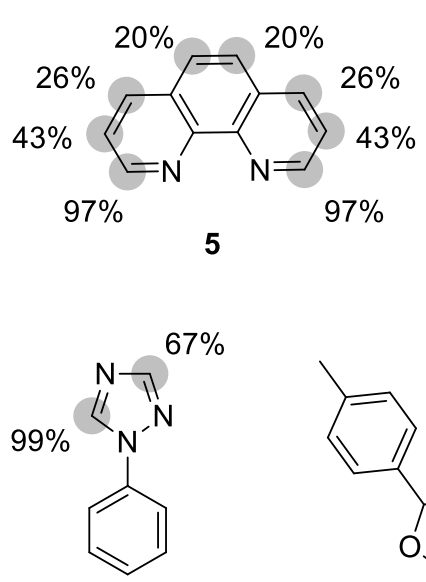

8
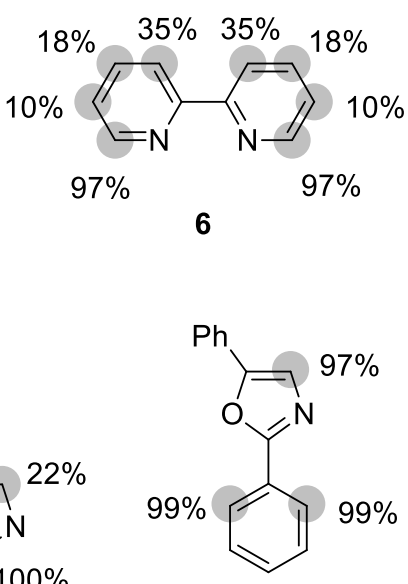

10

\section{Conclusions}

In conclusion, we report here the preparation of Ni@ NHC NPs by a controlled decomposition of the corresponding precursor under $\mathrm{H}_{2}$ in the presence of free NHC ligands. Magnetic measurements of the Ni@NHC NPs have been used for the first time to characterize the electronic features of the NHC ligand, showing that the presence of the IMes ligand induces a decrease of the magnetic susceptibility. We propose that this behavior may be linked to the higher $\pi$-acceptor ability of IMes. The activity of Ni@NHC NPs in the C-H activation for the selective H/D exchange of 2-phenylpyridine has been explored. Firstly, this system is fully selective for aromatic rings deuteration and does not lead to side-reduction products. This selectivity is of interest for pharmaceutical products in which active principles frequently contain such aromatic rings. It is furthermore possible to control the selectivity of deuteration according to the nature of the NHC ligand, IMes allowing a more extensive deuteration of a variety of molecules than ICy. Finally, the system displays a tolerance to oxygen, which can make it of practical interest. Overall, we propose a catalytic system based on Ni@ NHC NPs, which constitutes a less-costly alternative to noble metal catalysts and which displays a high 
activity and a controlled selectivity for deuteration reactions. A rapid screening of the scope of substrates shows that Ni@NHC NPs are very promising catalysts for the selective H/D exchange of challenging molecules.

\section{Conflicts of interest}

The authors declare no conflict of interest.

\section{Acknowledgements}

The authors thank ERC Advanced Grant (MONACAT 2015-694159). D. Bouzouita, V. Pfeifer and A. Palazzolo are participants in the EU Isotopics consortium. The ISOTOPICS project has received funding from the European Union Horizon2020 research and innovation program under the Marie Sklodowska-Curie grant agreement N88675071.

\section{References}

1. J. Atzrodt, V. Derdau, T. Fey and J. Zimmermann, Angew. Chem., Int. Ed., 2007, 46, 77447765.

2. J. Atzrodt, V. Derdau, W. J. Kerr and M. Reid, Angew. Chem., Int. Ed., 2018, 57, 1758-1784.

3. D. H. Phillips, G. A. Potter, M. N. Horton, A. Hewer, C. Crofton-Sleigh, M. Jarman and S. Venitt, Carcinogenesis, 1994, 15, 1487-1492.

4. J. Atzrodt, V. Derdau, W. J. Kerr and M. Reid, Angew. Chem., Int. Ed., 2017, 57, 3022-3047.

5. R. Heys, J. Chem. Soc., Chem. Commun., 1992, 680-681.

6. D. Hesk, P. R. Das and B. Evans, J. Labelled Compd. Radiopharm., 1995, 36, 497-502.

7. L. Neubert, D. Michalik, S. Baehn, S. Imm, H. Neumann, J. Atzrodt, V. Derdau, W. Holla and M. Beller, J. Am. Chem. Soc., 2012, 134, 12239-12244.

8. W. Bai, K.-H. Lee, S. K. S. Tse, K. W. Chan, Z. Lin and G. Jia, Organometallics, 2015, 34, 36863698.

9. $\quad$ E. Khaskin and D. Milstein, ACS Catal., 2013, 3, 448-452.

10. S. Chen, G. Song and X. Li, Tetrahedron Lett., 2008, 49, 6929-6932.

11. H. Yang, P. G. Dormer, N. R. Rivera and A. J. Hoover, Angew. Chem., Int. Ed., 2018, 57, 18831887.

12. A. J. Hickman, M. A. Cismesia and M. S. Sanford, Organometallics, 2012, 31, 1761-1766.

13. H. Yang, C. Zarate, W. N. Palmer, N. Rivera, D. Hesk and P. J. Chirik, ACS Catal., 2018, 8, 10210-10218.

14. C. Zarate, H. Yang, M. J. Bezdek, D. Hesk and P. J. Chirik, J. Am. Chem. Soc., 2019, 141, 50345044.

15. V. Derdau, J. Atzrodt, J. Zimmermann, C. Kroll and F. Brueckner, Chem. - Eur. J., 2009, 15, 10397-10404.

16. F. T. Jere, D. J. Miller and J. E. Jackson, Org. Lett., 2003, 5, 527-530.

17. W.-M. Yau and K. Gawrisch, J. Labelled Compd. Radiopharm., 1999, 42, 709-713.

18. J. R. Heys, J. Labelled Compd. Radiopharm., 2010, 53, 716-721.

19. T. Pery, K. Pelzer, G. Buntkowsky, K. Philippot, H.-H. Limbach and B. Chaudret, ChemPhysChem, 2005, 6, 605-607.

20. N. Rothermel, T. Roether, T. Ayvali, L. M. Martinez-Prieto, K. Philippot, H.-H. Limbach, B. Chaudret, T. Gutmann and G. Buntkowsky, ChemCatChem, 2019, 11, 1465-1471.

21. H.-H. Limbach, T. Pery, N. Rothermel, B. Chaudret, T. Gutmann and G. Buntkowsky, Phys. Chem. Chem. Phys., 2018, 20, 10697-10712. 
22. L. M. Martinez-Prieto and B. Chaudret, Acc. Chem. Res., 2018, 51, 376-384.

23. F. Zaera, ACS Catal., 2017, 7, 4947-4967.

24. D. Pla and M. Gomez, ACS Catal., 2016, 6, 3537-3552.

25. J. M. Asensio, D. Bouzouita, P. W. N. M. van Leeuwen and B. Chaudret, Chem. Rev., 2020, 120, 1042-1084.

26. N. Rothermel, D. Bouzouita, T. Roether, I. de Rosal, S. Tricard, R. Poteau, T. Gutmann, B. Chaudret, H.-H. Limbach and G. Buntkowsky, Chem CatChem, 2018, 10, 4243-4247.

27. G. Pieters, C. Taglang, E. Bonnefille, T. Gutmann, C. Puente, J.-C. Berthet, C. Dugave, B. Chaudret and B. Rousseau, Angew. Chem., Int. Ed., 2014, 53, 230-234.

28. D. Bouzouita, G. Lippens, E. A. Baquero, P. F. Fazzini, G. Pieters, Y. Coppel, P. Lecante, S. Tricard, L. M. Martinez-Prieto and B. Chaudret, Nanoscale, 2019, 11, 16544-16552.

29. C. Taglang, L. M. Martinez-Prieto, I. del Rosal, L. Maron, R. Poteau, K. Philippot, B. Chaudret, S. Perato, A. Sam Lone, C. Puente, C. Dugave, B. Rousseau and G. Pieters, Angew. Chem., Int. Ed., 2015, 54, 10474-10477.

30. E. Breso-Femenia, C. Godard, C. Claver, B. Chaudret and S. Castillón, Chem. Commun., 2015, 51, 16342-16345.

31. D. Gonzalez-Galvez, P. Lara, O. Rivada-Wheelaghan, S. Conejero, B. Chaudret, K. Philippot and P. W. N. M. van Leeuwen, Catal. Sci. Technol., 2013, 3, 99-105.

32. Q. Zhao, G. Meng, M. Szostak and S. P. Nolan, Chem. Rev., 2020, 120, 1981-2048.

33. M. N. Hopkinson, C. Richter, M. Schedler and F. Glorius, Nature, 2014, 510, 485-496.

34. C. A. Smith, M. R. Narouz, P. A. Lummis, I. Singh, A. Nazemi, C.-H. Li and C. M. Crudden, Chem. Rev., 2019, 119, 4986-5056.

35. A. Cervantes-Reyes, F. Rominger and A. S. K. Hashmi, Chem. - Eur. J., 2020, 26, 5530-5540.

36. A. Cervantes-Reyes, F. Rominger, M. Rudolph and A. S. K. Hashmi, Adv. Synth. Catal., 2020, 362, 2523-2533.

37. Q. Liang and D. Song, Chem. Soc. Rev., 2020, 49, 1209-1232.

38. A. Cervantes-Reyes, F. Rominger, M. Rudolph and A. S. K. Hashmi, Chem. - Eur. J., 2019, 25, 11745-11757.

39. L. S. Ott, M. L. Cline, M. Deetlefs, K. R. Seddon and R. G. Finke, J. Am. Chem. Soc., 2005, 127, 5758-5759.

40. D. Gonzalez-Galvez, P. Lara, O. Rivada-Wheelaghan, S. Conejero, B. Chaudret, K. Philippot and P. W. N. M. van Leeuwen, Catal. Sci. Technol., 2013, 3, 99-105.

41. E. A. Baquero, S. Tricard, J. C. Flores, E. de Jesus and B. Chaudret, Angew. Chem., Int. Ed., 2014, 53, 13220-13224.

42. J. M. Asensio, S. Tricard, Y. Coppel, R. Andrés, B. Chaudret and E. de Jesús, Angew. Chem., Int. Ed., 2017, 56, 865-869.

43. J. M. Asensio, S. Tricard, Y. Coppel, R. Andrés, B. Chaudret and E. de Jesús, Chem. - Eur. J., 2017, 23, 13435-13444.

44. K. Salorinne, R. W. Y. Man, C.-H. Li, M. Taki, M. Nambo and C. M. Crudden, Angew. Chem., Int. Ed., 2017, 56, 6198-6202.

45. L. M. Martínez-Prieto, E. A. Baquero, G. Pieters, J. C. Flores, E. de Jesús, C. Nayral, F. Delpech, P. W. N. M. van Leeuwen, G. Lippens and B. Chaudret, Chem. Comm., 2017, 53, 5850-5853.

46. A. Palazzolo, S. Feuillastre, V. Pfeifer, S. Garcia-Argote, D. Bouzouita, S. Tricard, C. Chollet, E. Marcon, D.-A. Buisson, S. Cholet, F. Fenaille, G. Lippens, B. Chaudret and G. Pieters, Angew. Chem., Int. Ed., 2019, 58, 4891-4895.

47. M. D. de los Bernardos, S. Perez-Rodriguez, A. Gual, C. Claver and C. Godard, Chem. Commun., 2017, 53, 7894-7897.

48. D. Jiles, Introduction to Magnetism and Magnetic Materials, Third Edition, CRC Press, 2015.

49. I. M. L. Billas, A. Chatelain and W. A. de Heer, Science, 1994, 265, 1682-1684.

50. W. Goepel, Surf. Sci., 1979, 85, 400-412.

51. N. Cordente, C. Amiens, B. Chaudret, M. Respaud, F. Senocq and M. J. Casanove, J. Appl. Phys., 2003, 94, 6358-6365. 
52. O. Back, M. Henry-Ellinger, C. D. Martin, D. Martin and G. Bertrand, Angew. Chem., Int. Ed., 2013, 52, 2939-2943.

53. G. Wang, A. Ruehling, S. Amirjalayer, M. Knor, J. B. Ernst, C. Richter, H.-J. Gao, A. Timmer, H.Y. Gao, N. L. Doltsinis, F. Glorius and H. Fuchs, Nat. Chem., 2017, 9, 152-156.

54. L. M. Martinez-Prieto, A. Ferry, L. Rakers, C. Richter, P. Lecante, K. Philippot, B. Chaudret and F. Glorius, Chem. Commun., 2016, 52, 4768-4771.

55. V. Pfeifer, M. Certiat, D. Bouzouita, A. Palazzolo, S. Garcia-Argote, E. Marcon, D.-A. Buisson, P. Lesot, L. Maron, B. Chaudret, S. Tricard, I. del Rosal, R. Poteau, S. Feuillastre and G. Pieters, Chem. - Eur. J., 2020, 26, 4988-4996. 